\title{
Changes in Cuticular Compounds of Developing Pecan Leaves
}

\author{
O.T. Chortyk and I.E. Yates \\ R. B. Russell Agricultural Research Center, Agricultural Research Service, U.S. Department ofAgriculture, \\ Athens, GA 30613 \\ C.C. Reilly \\ Southeastern Fruit and Tree Nut Laboratory. Agricultural Research Service, U.S. Department of \\ Agriculture, Byron, GA 31008
}

\begin{abstract}
Additional index words. Carya illinoensis, Cladosporium caryigenum, hydrocarbon, wax ester, triterpenoid, aliphatic alcohol, fatty acid and diacyl glyceride

Abstracl. Leaf surface compounds of pecan [Carya illinoensis (Wangenh.) C. Koch] were analyzed with regard to developmental stage and to susceptibility to infection by Cladosporium caryigenum (Ell. et Lang. Gottwald). Immature and mature leaves of two resistant ('Elliott' and 'Sumner') and two susceptible ('Wichita' and 'Schley') cultivars were extracted with methylene chloride. Extracts were separated by silicic acid chromatography into polar and nonpolar fractions. Constituents of each fraction were subsequently separated by gas chromatography and were identified by gas chromatography-mass spectroscopy. Leaf surface constituents characterized included long-chain aliphatic hydrocarbons, aliphatic wax esters, triterpenoid constituents, aliphatic alcohols, fatty acids, and diacyl glycerides. The predominant surface compounds on immature leaves were lipids such as fatty acids, fatty alcohols, and glycerides. On mature leaves, lipids declined and aliphatic hydrocarbons and triterpenoids became predominant leaf surface constituents. The changes were observed for all cultivars, regardless of genotypic response to $C$. caryigenum. Thus, we conclude that cuticular chemicals change dramatically during leaf maturation but do not correlate with resistance to scab disease common to certain pecan cultivars.
\end{abstract}

Pecan is a native North American plant species of the hickory (Carya) genus that has been developed to produce a ready cash crop for growers. However, in regions with humid weather, pecan scab caused by the fungus Cladosporium caryigenum (Ell. et Lang. Gottwald) can dramatically decrease the nut crop. Resistance to scab disease exists within pecan germplasm, but resistance [actors to scab infection have not been identified. Two proposals have been developed regarding the chemical bases of resistance: one concentrated on juglone (Hedin et al., 1979) and the other on unidentified leaf surface substances (Wood et al., 1988).

Juglone is a polyphenol with toxic properties and the recognized signature metabolic of pecan, walnut. and hickory species (Bell, 1981). Juglone has been implicated in scab resistance (Hedin, et al., 1979). The premise was that high levels of juglone in pecan leaves would cenfer resistance to scab disease. In our initial study (Gueldner et al., 1994), we evaluated polyphenols in relation to genotypic susceptibility to infection by the fungus causing pecan scab. Samples were taken during and after the period of scab infection. which generally starts 2 weeks after budbreak and continues for 6 weeks. The results indicated that, contrary to the previously held theory, levels of juglone $(1,5-$ dihydroxy-naphthoquinone) and hydrojuglone glucoside (4,8dihydroxy-1-naphthyl-(3-D-glucopyranoside) did not have any significant relationships to scab infection. Thus, we concluded that endogenous levels of these compounds in the pecan leaf could not account for genotypic response to $C$. caryigenum.

Wood et al. (1988) proposed that factors, other than juglone, present on pecan leaf surfaces were likely to be involved in resistance of pecan foliage and nuts to scab. No other studies have

Received for publication 28 July 1994. Accepted for publication 26001.1994 . The most able technical assistance of P.F. Mason in providing mass spectrat data is gratefully achnowledged. The cost of publishng this paper was def rayed in part by the payment of page charges. Linder postal regulations, this paper therefore must be hereby marked advertisement solely to indicate this fact. appeared clarifying any possible relationships of constituents on the surface of scab-resistant pecan leaves to disease development. As our initial study had evaluated the interior leaf phenolic compounds, this study was undertaken to determine the constituents on the leaf surface 01 developing pecan leaves. Thus, the objectives of this study were to characterize the constituents on the surface of the developing pecan leaf in several common pecan cultivars and to analyze possible differences in concentrations of compounds on scab-susceptible vs. scab-resistant pecan cultivars (Thompson and Grauke, 1990). This study is a continuation of our efforts to understand the chemical constituents within and on the surface of pecan leaves in relation to leaf development and possibly to susceptibility to fungal scab infection.

\section{Materials and Methods}

Sample collection. Two highly resistant ('Elliott' and 'Sumner') and two highly susceptible ('Schley' and 'Wichita') cultivars to scab disease development were selected for chemical analyses. Collections were taken from the first cycle of shoot growth around each tree from the northern, eastern, southern, and western sides with each tree representing a replication. Plant material was collected from 16-year-old trees at the Southeastern Fruit and Tree Nut Laboratory in Byron, Ga. Leaf material had no microscopically visible evidence of disease, insect, or mechanical injury and bad no chemical sprays applied. The objective of the study was to determine the leaf surface chemistry without confounding injury response by scab disease or any other damage.

Leaves from four trees of each cultivar were sampled in 1993 on 14 Apr., 28 Apr., 12 May, and 9 June. Sampling dates were selected to represent the spectrum of leaf development over which leaves of susceptible cultivars could be infected by $C$. caryigenum and then into maturity. when they develop resistance (Demaree, 1924). Development of the leaves over these sampling times progressed from immature and partially expanded in April to mature and fully 
expanded in June. Leaves of susceptible cultivars are subject to infection when less than $\approx 28$ days old (Demaree, 1924). The first sampling date was $\approx 2$ weeks after budbreak and corresponds to the period that black circular lesions would be visible, indicating infection by $C$. caryigenum. The second date corresponded to maximum scab growth, whereas, the third date would coincide with the decline of scab disease. The fourth date corresponded to a full y mature pecan leaf, which is resistant to scab in all pecan cultivars.

The third leaves from the base of the developing-shoots were collected to total 2 to $2.5 \mathrm{~g}$ of sample per tree. Leaves were weighed on an analytical balance and leaf surface areas were measured with an area meter (LI-3000, Lambda Instrument Corp., Lincoln, Neb.) to calculate the concentration of compounds on the basis of pg.cm ${ }^{2}$ leaf surface. Leaf surface extracts were obtained by placing 6 to 24 leaflets (depending on leaf maturity) into 118-ml amber glass bottles containing $100 \mathrm{ml}$ of methylene chloride (Fig. 1 ) and gently shaking the bottles $\approx 25$ times. Leaves were removed with forceps and the bottles were closed with a cap containing a Teflon liner (Scientific Specialties Services, Randallstown, Md.). Extracts were placed in a freezer until analyzed.

Silicic acid chromatography. On the day of analysis, the methylene chloride extracts $(100 \mathrm{ml})$ were evaporated to dryness and internal standards were added. Internal standards used were ndocosane for nonpolar compounds and 1-octadecanol for polar compounds at concentrations of 0.8346 and $0.8334 \mathrm{mg} \cdot \mathrm{ml}^{-1}$, respectively. The volume of internal standard added to the sample was adjusted on the basis of area of pecan leaf extracted using $\approx 4$ $\mu l$ internal standard $/ \mathrm{cm}^{2}$ leaf area.

After evaporation, the methylene chloride extract was redissolved in $500 \mu \mathrm{l}$ of 3 hexane : 1 methylene chloride (v/v). The extract was separated into polar and nonpolar fractions on a microsilicic acid column ( 100 to 200 mesh, activated Unisil silicic acid, Clarkson Chemical Company, Williamsport, Pa.) contained in a 6-mm-id. disposable borosilicate glass pipette. The column was prepared by packing a $1-\mathrm{cm}^{2}$ piece of Whatman No. 4 filter paper into the pipette base, followed by a $1-\mathrm{cm}$ plug of cellulose tissue, and then $0.5 \mathrm{~g}$ of silicic acid. After packing, the column was washed with 7 methylene chloride :2 acetone : 1 methanol (by volume) and reactivated overnight at $150 \mathrm{C}$. The leaf extract was applied to the column and hydrocarbons and wax esters were eluted in the nonpolar fraction A (Fig. 1 ) with $5 \mathrm{ml}$ of 3 hexane : 1 methylene chloride. The subsequent fraction B of polar compounds was eluted with $7 \mathrm{ml}$ of 7 methylene chloride :2 acetone :1 methanol (by volume).

Gas chromatography $(G C)$. The nonpolar and polar fractions from the silicic acid separation were evaporated to dryness on a heating block under a stream of $\mathrm{N}_{2}$. The dried samples were solubilized in benzene using $500 \mu \mathrm{l}$ of benzene for the nonpolar and $700 \mu \mathrm{l}$ for the polar fractions. Then $100 \mu \mathrm{l}$ of the polar fraction and $200 \mu \mathrm{l}$ of the nonpolar fraction were transferred to microautosampler vials (Hewlett-Packard Co., Wilmington, Del.). Samples were again dried under a stream of $\mathrm{N}_{2}$ and treated with 50 $\mu \mathrm{l}$ of $\mathrm{N}, \mathrm{O}$-bis(trimethylsilyl)-acetamide (BSA) to convert the compounds to their trimethylsilyl derivatives. The vials were capped and heated for $45 \mathrm{~min}$ at $76 \mathrm{C}$. After cooling, $1-\mu$ samples were analyzed by GC (HP 5890A gas chromatography equipped with an HP7673 automatic sampler and a flame ionization detector, Hewlett-Packard) (Fig. 1). Injection port temperature was $250 \mathrm{C}$ and detector temperature was 330C. The nonpolar fraction was analyzed on a $0.52-\mathrm{mm} \times 12-\mathrm{m}$ wide bore, thin-film, bonded

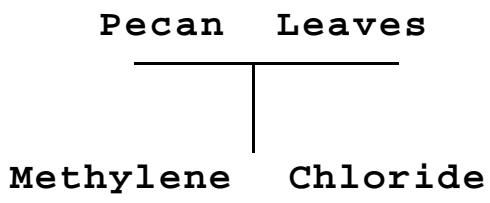

$\mathrm{CH}_{2} \mathrm{Cl}_{2} \quad \mathrm{ExtraCt}$

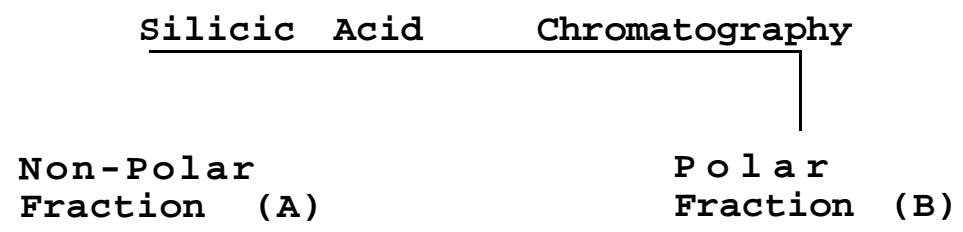

Gas Chromatography

G C / M S
Gas Chromatography

G C / M S

\section{Aliphatic Hydrocarbons Wax Esters}

Aliphatic Alcohols
Fatty Acids
Diglycerides
Triterpenols
Triterpenoid Acids

Fig. 1. Isolation and identification scheme for cuticular compounds of pecan leaves. 
SE 54 fused silica column with $\mathrm{He}$ as the carrier gas at a flow rate of $\approx 20 \mathrm{ml} \cdot \mathrm{min}^{-1}$. Column temperature was held at $100 \mathrm{C}$ for 30 see, then programmed from 100 to $330 \mathrm{C}$ at $8 \mathrm{C} / \mathrm{min}$ and held for $5 \mathrm{~min}$ at $330 \mathrm{C}$. The polar compounds were analyzed on a $30-\mathrm{m} \times 0.32-$ $\mathrm{mm}$ thin-film (0.1 micron) bonded SE 54 fused silica capillary glass column. The flow rate of $\mathrm{H}$, carrier was $40 \mathrm{~cm} \cdot \mathrm{s}^{-1}$. Column temperature was held at $100 \mathrm{C}$ for $1 \mathrm{~min}$, programmed to $170 \mathrm{C}$ at $10 \mathrm{C} / \mathrm{min}$, then programmed to $330 \mathrm{C}$ at $6 \mathrm{C} / \mathrm{min}$, and held for $10 \mathrm{~min}$ at the upper temperature. GC data were collected in Chrom Perfect (Justice Innovations, Palo Alto, Calif.) and data were calculated as concentration of compounds at $\mu \mathrm{g} \cdot \mathrm{cm}^{-2}$ of leaf surface. Gas chromatographic method reproducibility was excellent; the use of the automatic sampler reduced reproducibility errors to $2 \%$ or less. However, comparison of analytical data from the collected leaf samples revealed that there was usually a wide variation in the quantitative data $\left(\mu \mathrm{g} \cdot \mathrm{cm}^{-2}\right)$ from one of the four trees sampled, giving data that deviated from $10 \%$ to $70 \%$, compared to the data for the other trees. As a result, the percent relative standard deviations (RSDs) of individual compound levels varied from $7 \%$ to $45 \%$, with an average RSD of $<19 \%$ as determined by appropriate statistical analysis (Gomez and Gomez, 1984).

GC-mass spectrometry (MS). Nonpolar and polar fractions were analyzed with a Hewlett Packard 5989A GC-MS. Total ion chromatograms on these fractions were obtained. The GC-MS interface temperature was $280 \mathrm{C}$, the ion source temperature was 250C, and the electron impact (ET) ionization energy was $70 \mathrm{eV}$ for each analysis. Other MS conditions for the analyses of trimethylsilyl ether derivatives were scan range, 40 to $650 \mathrm{Da}, 0.88 \mathrm{scans} / \mathrm{see}$, electron multiplier voltage 1866 volts. GC-MS data were compared to those of standard compounds run under identical conditions of analysis.

\section{Results and Discussion}

Nonpolar compounds. The long-chain aliphatic hydrocarbon constituents varied from the $\mathrm{C}_{19}$ hydrocarbon up to the $\mathrm{C}_{33}$ hydrocarbon in 'Elliott' and 'Wichita' (Tables 1 and 2, respectively). The predominant compounds on the immature leaf surfaces 2 weeks after budbreak were the odd hydrocarbons, $\mathrm{C}_{25}, \mathrm{C}_{27}$, and $\mathrm{C}_{29}$. As the leaf developed, $\mathrm{C}_{27}, \mathrm{C}_{29}$, and $\mathrm{C}_{31}$ hydrocarbon levels drastically increased and became the predominant compounds. For resistant 'Elliott', concentration of the most abundant hydrocarbon, $\mathrm{C}_{31}$, increased 20 -fold from 0.13 to $2.98 \mu \mathrm{g} \cdot \mathrm{cm}^{-2}$ as leaf development progressed from immature on $14 \mathrm{Apr}$. to mature leaf on 9 June (Table 1). The next most abundant hydrocarbon, $\mathrm{C}_{29}$, increased $\approx 10$-fold from 0.27 to $2.48 \mu \mathrm{g} \cdot \mathrm{cm}^{-2}$. On mature leaves by 9 June, the odd numbered hydrocarbons accounted for $91 \%$ of the total hydrocarbons and constituted the major compounds in this fraction. Perhaps these hydrocarbons develop as a protective mechanism for leaf surfaces by preventing transpiration.

The other group of compounds in the nonpolar fraction were the wax esters, which are esters of long chain aliphatic acids with fatty alcohols. Their concentration was relatively constant throughout leaf development and averaged less than $0.1 \mu \mathrm{g} \cdot \mathrm{cm}^{-2}$. Wax esters were present in trace amounts of up to $0.2 \mu \mathrm{g} \cdot \mathrm{cm}^{-2}$ and ranged from $\mathrm{C}_{35}$ to $\mathrm{C}_{52}$ compounds, with the predominant wax ester being the $\mathrm{C}_{35}$ compound. The composition of the nonpolar or hydrocarbonwax ester fraction resembled paraffinic hydrocarbons and wax esters observed for other plants, such as tobacco (Arrendale et al., 1988). The hydrocarbon-wax ester data for the resistant 'Sumner' were very similar to those for 'Elliott' and, thus, are not presented.

The aliphatic hydrocarbons constituents in the susceptible 'Wichita' were similar to those of the resistant 'Elliott' and also

Table 1. Concentations ${ }^{2}$ of nonpolar cuticular compounds on developing 'Elliott' pecan leaves.

\begin{tabular}{|c|c|c|c|c|c|}
\hline Compound & $\begin{array}{c}\text { No. of } \\
\text { carbons }\end{array}$ & 14 Apr. & 28 Apr. & 12 May & 9 June \\
\hline Nonadecane & 19 & $\mathrm{ND}^{\mathrm{y}}$ & $++^{x}$ & 0.12 & + \\
\hline Eicosane & 20 & ND & 0.04 & 0.02 & + \\
\hline Heneicosane & 21 & + & 0.04 & 0.04 & + \\
\hline Tricosane & 23 & 0.32 & 0.13 & 0.05 & 0.03 \\
\hline Tetracosane & 24 & 0.06 & 0.03 & 0.08 & 0.06 \\
\hline Pentacosane & 25 & 0.55 & 0.61 & 0.42 & 0.36 \\
\hline Hexacosane & 26 & 0.08 & 0.09 & 0.05 & 0.07 \\
\hline Heptacosane & 27 & 0.64 & 0.85 & 0.89 & 1.03 \\
\hline Octacosane & 28 & 0.08 & 0.11 & 0.12 & 0.16 \\
\hline Nonacosane & 29 & 0.27 & 0.78 & 1.57 & 2.48 \\
\hline Triacontane & 30 & 0.04 & 0.04 & 0.12 & 0.23 \\
\hline Hentriacontane & 31 & 0.13 & 0.29 & 1.83 & 2.98 \\
\hline Dotriacontane & 32 & 0.03 & + & 0.07 & 0.21 \\
\hline Tritriacontane & 33 & 0.06 & 0.10 & 0.42 & 0.33 \\
\hline $\mathrm{C}_{35}$-wax ester & 35 & 0.06 & 0.02 & 0.16 & 0.13 \\
\hline $\mathrm{C}_{36}$-wax ester & 36 & 0.09 & + & 0.04 & ND \\
\hline $\mathrm{C}_{38}$-wax ester & 38 & 0.09 & + & 0.04 & 0.12 \\
\hline $\mathrm{C}_{40}$-wax ester & 40 & 0.06 & ND & 0.03 & 0.09 \\
\hline $\mathrm{C}_{42}$-wax ester & 42 & 0.03 & 0.07 & 0.04 & 0.03 \\
\hline $\mathrm{C}_{44}$-wax ester & 44 & 0.04 & 0.08 & 0.03 & 0.04 \\
\hline $\mathrm{C}_{46}$-wax ester & 46 & 0.03 & 0.05 & 0.08 & 0.08 \\
\hline $\mathrm{C}_{48}$-wax ester & 48 & + & 0.02 & 0.06 & 0.08 \\
\hline $\mathrm{C}_{50}$-wax ester & 50 & + & ND & 0.09 & 0.04 \\
\hline $\mathrm{C}_{52}$-wax ester & 52 & ND & ND & + & 0.02 \\
\hline
\end{tabular}

${ }^{2}$ Concentration expressed as $\mathrm{mg} \cdot \mathrm{cm}^{-2}$ of leaf area and is the average of four tree replications.

${ }^{\mathrm{N} D}=$ not detected.

$\mathrm{x}(+)=$ Trace quantities of $<0.02 \mu \mathrm{g} \cdot \mathrm{cm}^{-2}$. 
ranged from $\mathrm{C}_{19}$ to $\mathrm{C}_{33}$ hydrocarbons (Table 2). The major hydrocarbons were $\mathrm{C}_{29}$ and $\mathrm{C}_{31}$, and these increased from levels of $\approx 0.15$ to $\gg 1.11 \mu \mathrm{g} \cdot \mathrm{cm}^{-2}$ for the $\mathrm{C}_{29}$ hydrocarbon and from 0.11 to 2.8 $\mu \mathrm{g} \cdot \mathrm{cm}^{-2}$ for $\mathrm{C}_{31}$ hydrocarbon from the starting immature to the final mature leaves. Concentration of $\mathrm{C}_{31}$ hydrocarbon was the same as in 'Elliott', but the $\mathrm{C}_{27}$ and $\mathrm{C}_{29}$ hydrocarbons were at half the 'Elliott' amounts. The-significance of this is not understood. The wax esters in 'Wichita' ranged from $\mathrm{C}_{35}$ to $\mathrm{C}_{52}$ compounds, as in 'Elliott'. Very similar concentrations and trends of hydrocarbons and wax esters during leaf development were observed for the other susceptible cultivar, Schley.

Immature, developing leaf surfaces for all four cultivars had relatively low coatings of hydrocarbons and wax esters, which increased dramatically when the leaf reached maturity. These chemicals likely form protective layers for maintaining leaf moisture as temperatures increase during the growing season. Furthermore, the increase in the waxy coating at the later stages in leaf development may cause the mature leaf to become more impenetrable to the scab fungus. At this point, no relationships among the four pecan cultivars could be observed to account for scab susceptibility vs. resistance at the earlier sampling dates when such responses would be expressed.

Polar compounds. The polar constituents of the cuticular pecan leaf compounds (Tables 3 and 4) were much more complex than the nonpolar fraction. Constituents of the polar fraction included aliphatic alcohols, unsaturated and saturated fatty acids, discyl glycerides, and terpenoid compounds. The first constituent observed in the gas chromatogram for leaves of resistant 'Elliott' was tentatively identified as 7-methyl-7-hydroxy octanoic acid, an unusual hydroxy acid (Table 3). At first, this compound was suspected as a potential scab resistance factor. However, due to its absence in the polar fraction of resistant 'Sumner', this acid could not be linked to resistance. For 'Elliott', the major polar compounds at the first sampling date were comprised of alcohols, glycerides, and three unknown compounds believed to be similar phenolic compounds: a chalcone, a flavanone, and a flavone. This group of compounds was isolated by repetitive column chromatography on silicic acid to give a highly enriched fraction. Reversephase liquid chromatography on an HP7050 instrument equipped with a $\mathrm{C}_{18}$-ultrasphere ODS column produced ultraviolet spectra highly characteristic of the above compounds. GC-MS data yielded fragmentation patterns very similar to library spectra for 2',6'dihydroxy-4'-methoxy-chalcone, 3,4-dihydro-5,7-dihydroxy-8 methyl-2H-1-benzopyran-6-carbox aldehyde, and 4',5-dihydroxy6,7-dimethoxy-flavone. As standard compounds were unavailable for comparison, absolute identification cannot be claimed.

Almost all of the even-numbered alcohols, from $\mathrm{C}_{14}$ to $\mathrm{C}_{32}$, were present, as well as some of the odd-numbered alcohols $\left(\mathrm{C}_{23}, \mathrm{C}_{27}\right.$, and $\mathrm{C}_{29}$ ). The high initial concentrations of the $\mathrm{C}_{24}$ and $\mathrm{C}_{26}$ alcohols, 1.51 and $1.04 \mu \mathrm{g} \cdot \mathrm{cm}^{-2}$, respectively, decreased dramatically with leaf development. Concentration of the odd alcohols were lower initially and decreased relatively less drastically. Thus, alcohols initially present at low concentrations generally remained low. These included the $\mathrm{C}_{14}, \mathrm{C}_{16}, \mathrm{C}_{20}$, and $\mathrm{C}_{23}$ alcohols. Alcohols in higher concentrations on immature leaves, such as the $\mathrm{C}_{24}, \mathrm{C}_{26}, \mathrm{C}_{28}$, and $\mathrm{C}_{30}$ alcohols, decreased to less than $\approx 10 \%$ of their initial concentrations on mature leaves.

The polar fraction also contained a series of fatty acids. Fatty acids corresponding to some of the lower alcohols were observed and these included the $\mathrm{C}_{16}$ fatty acid, two $\mathrm{C}_{18}$ unsaturated fatty acids, (probably oleic and linoleic acids), the $\mathrm{C}_{18}$ saturated fatty acid, and the $\mathrm{C}_{20}$, fatty acid. All fatty acids were present in low quantities.

Table 2. Concentrations ${ }^{2}$ of nonpolar cuticular compounds on developing 'Wichita' pecan leaves.

\begin{tabular}{|c|c|c|c|c|c|}
\hline Compound & $\begin{array}{c}\text { No. of } \\
\text { carbons }\end{array}$ & 14 Apr. & 28 Apr. & 12 May & 9 June \\
\hline Nonadecane & 19 & $\mathrm{ND}^{\mathrm{y}}$ & ND & $+^{x}$ & + \\
\hline Eicosane & 20 & + & + & + & 0.03 \\
\hline Heneicosane & 21 & + & + & + & 0.02 \\
\hline Tricosane & 23 & 0.29 & 0.06 & + & 0.03 \\
\hline Tetracosane & 24 & 0.05 & + & 0.10 & 0.05 \\
\hline Pentacosane & 25 & 0.29 & 0.29 & 0.26 & 0.18 \\
\hline Hexacmane & 26 & 0.08 & 0.03 & 0.04 & 0.05 \\
\hline Heptacosane & 27 & 0.35 & 0.47 & 0.54 & 0.47 \\
\hline Octacosane & 28 & 0.10 & 0.05 & 0.05 & 0.09 \\
\hline Nonacnsane & 29 & 0.15 & 0.66 & 0.99 & 1.11 \\
\hline Triacontane & 30 & 0.05 & 0.04 & 0.09 & 0.17 \\
\hline Hentriacontane & 31 & 0.11 & 0.64 & 2.13 & 2.82 \\
\hline Dotriacontane & 32 & 0.04 & + & 0.05 & 0.07 \\
\hline Tritriacontane & 33 & 0.04 & 0.06 & 0.81 & 0.57 \\
\hline $\mathrm{C}_{35}$-wax ester & 35 & 0.08 & 0.02 & 0.20 & 0.10 \\
\hline $\mathrm{C}_{36}$-wax ester & 36 & 0.09 & + & 0.09 & \\
\hline $\mathrm{C}_{38}$-wax ester & 38 & 0.09 & + & 0.02 & 0.08 \\
\hline $\mathrm{C}_{40}$-wax ester & 40 & 0.06 & 0.07 & 0.04 & 0.15 \\
\hline $\mathrm{C}_{42}$-wax ester & 42 & 0.02 & 0.10 & 0.08 & 0.06 \\
\hline $\mathrm{C}_{44}$-wax ester & 44 & + & 0.08 & 0.06 & 0.03 \\
\hline $\mathrm{C}_{46}$-wax ester & 46 & 0.02 & 0.08 & 0.06 & 0.04 \\
\hline $\mathrm{C}_{48}$-wax ester & 48 & + & 0.04 & 0.20 & 0.10 \\
\hline $\mathrm{C}_{50}$-wax ester & 50 & + & ND & 0.07 & 0.02 \\
\hline $\mathrm{C}_{52}$-wax ester & 52 & ND & ND & 0.03 & + \\
\hline
\end{tabular}

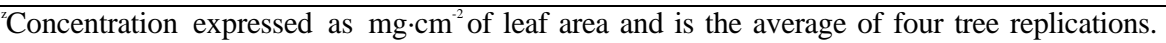

${ }^{y} \mathrm{ND}=$ not detected.

$\mathrm{x}(+)=$ Trace quantities of $<0.02 \mu \mathrm{g} \cdot \mathrm{m}^{-2}$. 
The presence of glycerides on the surface of the immature, green pecan leaves was unexpected. Glycerides that were identified included the $\mathrm{C}_{2}, \mathrm{C}_{16}$ diacyl glyceride, the 1,2 and 1,3 isomers of the $\mathrm{C}_{2}, \mathrm{C}_{18}$ diacyl glyceride, and the $\mathrm{C}_{2}, \mathrm{C}_{18}$-unsaturated diacyl glyceride. Two $\mathrm{CC}$ peaks that were identified corresponded to 1,2acetyl stearyl glyceride and 1,3-acetyl stearyl glyceride. As observed for the fatty acids and alcohols, glycerides also rapidly decreased after the first sampling date. This fact probably reflects lipid metabolism in the young pecan leaf. Although not listed in Table 3, very small concentrations of $\mathrm{C}_{28}, \mathrm{C}_{30}$, and $\mathrm{C}_{32}$ aldehydes were identified by GC-MS in the extract from the last two sampling dates. This should be expected, as substantial quantities of $\mathrm{C}_{24}, \mathrm{C}_{26}$ and $\mathrm{C}_{30}$, aldehydes have been reported in the cuticular compounds of walnut leaves (Prasad and Gulz, 1990).

Decreases in lipids were accompanied by increases in terpenoid constituents, as the leaf matured. For example, the triterpenoid compounds, $\alpha$ - and $\beta$ - amyrin and lupeol, were observed to increase from nondetectable concentrations for the first sampling date to very high $\left(2\right.$ to $\left.3 \mu \mathrm{g} \cdot \mathrm{cm}^{-2}\right)$ concentrations on the last sampling date. The compound previously characterized by our laboratory as Stuart triterpenol (Smith and Severson, 1992), has now been identified as the triterpenol, lupeol, by comparing its mass spectral fragmentation pattern with commercially purchased lupeol. Other triterpenoid compounds observed were erythrodiol, ursolic acid, oleanolic acid, hydroxy-ursolic acid, and hydroxy oleanolic. The last three triterpenoids were identified by MS data among the small peaks in the triterpenoid region of the gas chromatogram. The increases in the triterpenoids with leaf development were very striking. As a-amyrin occurs in plants as the acetate, the amyryl acetate identified is probably this isomer. MS data indicated the presence of $\beta$-sitosterol coeluting in the Bamyrin peak. The increases in waxy terpenoids may also be interpreted as a possible protective mechanism by the plant to exude leaf surface compounds to prevent loss of water by sealing the pores of the leaf. Ursolic acid occurs in the protective wax coating of fruits, such as apples and pears (Merck, 1993). The occurrence of monostearin at the last sampling dates maybe a clue to the disappearance of the $\mathrm{C}_{2}, \mathrm{C}_{18}$-diglycerides. The only unusual compound found, which belongs neither to the fatty acids nor terpenoid groups, was delta-tocopherol. This common member of the vitamin E complex is usually found in oils of soybeans, cottonseed, wheat germ, and peanut. Identical compounds and very similar concentrations and trends were found for resistant 'Sumner' and need not be discussed.

Table 3. Concentrations ${ }^{2}$ of polar cuticular compounds on developing 'Elliott' pecan leaves.

\begin{tabular}{|c|c|c|c|c|c|}
\hline Compound & $\begin{array}{l}\text { No. of } \\
\text { carbons }\end{array}$ & 14 Apr. & 28 Apr. & 12 May & 9 June \\
\hline 7-Methyl-7-hydroxy octanoic acid & 9 & 0.59 & 0.17 & 0.11 & 0.08 \\
\hline $\mathrm{C}_{14}$-alcohol & 14 & 0.04 & $+^{y}$ & + & 0.09 \\
\hline $\mathrm{C}_{16}$-alcohol & 16 & 0.06 & + & 0.04 & 0.04 \\
\hline $\mathrm{C}_{16}$-fatty acid & 16 & 0.35 & 0.20 & 0.26 & 0.21 \\
\hline $\mathrm{C}_{18}$-unsaturated fatty acid (oleic) & 18 & + & + & 0.16 & $\mathrm{ND}^{\mathrm{x}}$ \\
\hline $\mathrm{C}_{18}$-unsaturated fatty acid (linoleic) & 18 & + & + & 0.30 & + \\
\hline $\mathrm{C}_{18}$-fatty acid & 18 & 0.30 & 0.17 & 0.11 & 0.12 \\
\hline $\mathrm{C}_{20}$-alcohol & 20 & 0.03 & 0.03 & + & ND \\
\hline $\mathrm{C}_{20}$-fatty acid & 20 & ND & ND & 0.05 & 0.04 \\
\hline Unknown A & 16 & 0.74 & 0.42 & + & 0.04 \\
\hline Unknown B & 17 & 1.61 & 0.53 & 0.10 & ND \\
\hline Unknown $\mathrm{C}$ & 17 & 1.72 & 0.68 & ND & ND \\
\hline Diacyl $\left(\mathrm{C}_{2}, \mathrm{C}_{16}\right)$ glyceride & 21 & 0.39 & 0.13 & 0.03 & ND \\
\hline $\mathrm{C}_{23}$-alcohol & 23 & + & 0.11 & 0.05 & ND \\
\hline $\mathrm{C}_{14}$-alcohol & 24 & 1.51 & 1.14 & 0.26 & 0.20 \\
\hline 1-Monostearin & 21 & ND & ND & 0.04 & 0.04 \\
\hline Diacyl $\left(\mathrm{C}_{2}, \mathrm{C}_{18}\right)$ glyceride & 23 & 1.46 & 0.28 & 0.06 & 0.06 \\
\hline Diacyl $\left(\mathrm{C}_{2}, \mathrm{C}_{18}\right)$ glyceride & 23 & 0.86 & 0.35 & + & $\mathrm{ND}$ \\
\hline Delta-tocopherol & 27 & 0.37 & 0.29 & 0.23 & 0.21 \\
\hline Diacyl $\left(\mathrm{C}_{2}, \mathrm{C}_{18}=\right)$ glyceride & 23 & 0.15 & 0.13 & 0.05 & ND \\
\hline $\mathrm{C}_{26}$-alcohol & 26 & 1.04 & 0.84 & 0.37 & 0.12 \\
\hline $\mathrm{C}_{27}$-alcohol & 27 & ND & 0.13 & 0.07 & ND \\
\hline $\mathrm{C}_{28}$-alcohol & 28 & 0.54 & 0.41 & 0.24 & 0.07 \\
\hline $\mathrm{C}_{29}$-alcohol & 29 & ND & 0.10 & 0.10 & ND \\
\hline Amyryl acetate & 32 & ND & ND & + & 0.35 \\
\hline $\mathrm{C}_{30}$-alcohol & 30 & 0.34 & 0.39 & + & ND \\
\hline B-Amyrin & 30 & ND & ND & 1.25 & 2.41 \\
\hline$\alpha-$ Amyrin & 30 & ND & 0.17 & 0.22 & 1.49 \\
\hline Lupeol & 30 & ND & ND & 1.26 & 2.80 \\
\hline 24-Methylene-cycloartenol & 30 & ND & ND & 0.37 & 0.28 \\
\hline Erythrodiol & 30 & ND & ND & 0.05 & 0.11 \\
\hline $\mathrm{C}_{32}$-alcohol & 32 & 0.14 & 0.13 & 0.23 & 0.21 \\
\hline Ursolic acid & 30 & ND & ND & 0.08 & ND \\
\hline
\end{tabular}

${ }^{2}$ Concentration expressed as $\mathrm{mg} \cdot \mathrm{cm}^{-2}$ of leaf area and is the average of four tree replications,

$\mathrm{y}(+)=$ Trace quantities of $<0.02 \mu \mathrm{g} \cdot \mathrm{cm}^{-2}$.

${ }^{\mathrm{x}} \mathrm{ND}=$ not detected. 
Table 4. Concentrations ${ }^{2}$ of polar cuticular compounds on developing 'Wichita' pecan leaves.

\begin{tabular}{|c|c|c|c|c|c|}
\hline Compound & $\begin{array}{c}\text { No. of } \\
\text { carbons }\end{array}$ & 14 Apr. & 28 Apr. & 12 May & 9 June \\
\hline $\mathrm{C}_{14}$-alcohol & 14 & $++^{y}$ & + & $\mathrm{ND}^{\mathrm{x}}$ & ND \\
\hline $\mathrm{C}_{16}$-alcohol & 16 & + & + & + & + \\
\hline $\mathrm{C}_{16}$-fatty acid & 16 & 0.49 & 0.20 & 0.64 & 0.24 \\
\hline $\mathrm{C}_{18}$-unsaturated fatty acid (oleic) & 18 & + & + & 0.45 & + \\
\hline $\mathrm{C}_{18}$-unsaturated fatty acid (linoleic) & 18 & + & + & 0.78 & + \\
\hline $\mathrm{C}_{18}$-fatty acid & 18 & 0.36 & 0.19 & 0.27 & 0.27 \\
\hline $\mathrm{C}_{20}$-alcohol & 20 & 0.03 & 0.03 & ND & ND \\
\hline $\mathrm{C}_{20}$-fatty acid & 20 & + & + & 0.03 & ND \\
\hline Unknown A & 16 & 0.42 & 0.18 & ND & ND \\
\hline Unknown B & 17 & 1.12 & 0.35 & 0.22 & ND \\
\hline Unknown $\mathrm{C}$ & 17 & 1.12 & 0.50 & 0.24 & ND \\
\hline Diacyl $\left(\mathrm{C}_{2}, \mathrm{C}_{16}\right)$ glyceride & 21 & 0.56 & 0.24 & 0.07 & 0.04 \\
\hline $\mathrm{C}_{24}$-alcohol & 24 & 1.31 & 0.85 & 0.50 & 0.13 \\
\hline 1-Monostearin & 21 & ND & ND & 0.08 & 0.10 \\
\hline Diacyl $\left(\mathrm{C}_{2}, \mathrm{C}_{18}\right)$ glyceride & 23 & 1.44 & 0.42 & 0.26 & 0.16 \\
\hline Diacyl $\left(\mathrm{C}_{2}, \mathrm{C}_{18}\right)$ glyceride & 23 & 1.10 & 0.62 & 0.42 & 0.20 \\
\hline Delta-tocopherol & 27 & 0.32 & 0.13 & 0.21 & 0.12 \\
\hline Diacyl $\left(\mathrm{C}_{2}, \mathrm{C}_{18}=\right)$ glyceride & 23 & 0.06 & 0.02 & ND & ND \\
\hline $\mathrm{C}_{26}$-alcohol & 26 & 0.89 & 0.85 & 1.19 & 0.32 \\
\hline $\mathrm{C}_{27}$-alcohol & 27 & 0.06 & 0.12 & ND & ND \\
\hline $\mathrm{C}_{28}$-alcohol & 28 & 0.45 & 0.42 & 0.64 & 0.18 \\
\hline $\mathrm{C}_{29}$-alcohol & 29 & 0.03 & ND & ND & ND \\
\hline Amyryl acetate & 32 & ND & ND & ND & 0.46 \\
\hline $\mathrm{C}_{30}$-alcohol & 30 & 0.23 & 0.25 & + & + \\
\hline B-Amyrin & 30 & ND & + & 2.87 & 2.59 \\
\hline$\alpha-$ Amyrin & 30 & ND & ND & ND & 1.12 \\
\hline Lupeol & 30 & ND & 0.16 & 4.45 & 3.12 \\
\hline 24-Methylene-cycloartenol & 30 & ND & ND & 0.54 & 0.18 \\
\hline Erythrodiol & 30 & ND & ND & 0.06 & 0.11 \\
\hline $\mathrm{C}_{32}$-alcohol & 32 & 0.07 & 0.10 & 0.31 & 0.13 \\
\hline Ursolic acid & 30 & ND & ND & + & + \\
\hline
\end{tabular}

${ }^{2}$ Concentration expressed as $\mathrm{mg} \cdot \mathrm{cm}^{-2}$ of leaf area and is the average of four tree replications.

$\mathrm{y}(+)=$ Trace quantities of $<0.02 \mathrm{pg} \cdot \mathrm{cm}^{-2}$.

${ }^{\mathrm{x}} \mathrm{ND}=$ not detected.

The polar cuticular compounds on developing 'Wichita' pecan leaves (Table 4) were identical to those on 'Elliott'. Comparisons of polar compounds on 'Elliott' (Table 3) to 'Wichita' (Table 4) revealed very similar concentrations and trends with leaf age. Again, alcohols, fatty acids, glyceride, and triterpenoid compounds were observed. As for 'Elliott', 'Wichita' polar compounds followed similar trends of decreases in fatty acid-derived lipids and increases in the polar triterpenoid compounds with leaf growth and maturity. Thus, for example, the $\mathrm{C}_{24}$ alcohol decreased from a level of » $1.3 \mu \mathrm{g} \cdot \mathrm{cm}^{-2}$ on immature leaves (14 Apr.) to 0.13 $\mu \mathrm{g} \cdot \mathrm{cm}^{-2}$ on mature leaves (9 June). Similar decreases occurred in the other fatty acids and alcohols. The other major lipid compounds present on the immature leaves (14 Apr.) were the diacyl glycerides, which decreased 8 -fold from 3.16 to $\gg 0.40 \mu \mathrm{g} \cdot \mathrm{cm}^{-2}$, progressing with leaf maturation from 14 Apr. to 9 June. The presence of 1 -monostearin at the last two sampling dates and its absence in the first two sampling dates again indicates possible degradation of the $\mathrm{C}_{2}, \mathrm{C}_{18}$-diglyceride by the cleavage of the acetate group, leaving the monostearic acid glyceride intact. However, no monopalmitin was observed.

Increases in terpenoid compounds were very spectacular in 'Wichita', as observed for 'Elliott'. Their absence in the first two sampling dates combined with their large concentrations at the last two sampling dates indicates that these compounds may be end metabolizes of the isoprene biosynthesis system. For the 'Wichita' leaves, the large concentrations of $\beta$-amyrin, $\alpha-$ amyrin, lupeol, and amyryl acetate accounted for at least $80 \%$ of the polar constituents for mature leaves on 9 June sampling date. Such high concentrations of triterpenoids on leaf surfaces are not unusual. Even on wild citrus tree species, leaf waxes have been shown to contain $>65 \%$ $\alpha$-amyrin, $\beta$-amyrin, and lupeol in the cuticular extract (Gulz et al.. 1987). Compounds such as 24-methylene-cycloartenol, erythrodiol, ursolic acids, and oleanolic acid were the other terpenoid compounds that were found in significant amounts on the mature pecan leaf. Although not listed in Table 4, very small quantities of other triterpenoids such as hydroxy-amyrins, hydroxy-ursolic acid. and hydroxy-oleanolic acid were detected by mass spectrometry.

In summary, chemicals on the pecan leaf surface change qualitatively and quantitatively as development progresses from immature to mature leaf. The general pattern is a concentration increase in the nonpolar constituents and a decrease in polar constituents. However, specific chemicals within these two classes of compounds had different trends. In spite of the many consistent changes associated with leaf development, no relationship was apparent between leaf surface chemicals and genotypic susceptibility to scab disease. Resistant cultivars may produce specific defense compounds when subjected to fungal infections. As 1993 was a very dry year, no scab infections were noted and no specific 
defense compounds were found. Another possibility is that elicited phytoalexins are internal, water-soluble compounds, such as antifungal peptides. These compounds would not have been detected by our analyses. More research needs to be pursued in this area.

\section{Literature Cited}

Arrendale, R.F., R.F. Severson, O.T. Chortyk, and M.G. Stephenson. 1988. Isolation and identification of the wax esters from the cuticular waxes of green tobacco leaf. Beitr. Tabakforsch. 14(2):67-84.

Bell, E.A. 1981. The physiological role(s) of secondary (natural) products, p. 1- 19. In: P.K. Stumpf and E.E. Corm (eds.). The biochemistry of plants-A comprehensive treatise. vol. 7. Secondary plant products. Academic Press, New York.

Demaree, J.B. 1924. Pecan scab with special reference to sources of the early spring infections. J. Agr. Res. 28:321-329.

Gomez, K.A. and A.A. Gomez. 1984. Statistical procedures for agricultural research. Wiley, New York.

Gueldner, R. C., I.E. Yates, C.C. Reilly, B.W. Wood, and M.T. Smith.
1994. Concentrations of a hydrojuglone glucoside in developing pecan leaves in relation to scab susceptibility. J. Amer. Soc. Hort. Sci. 119:498-504.

Gulz, P.-G., R.W. Scora, E. Muller, and F.J. Marner. 1987. Epicuticular leaf waxes of Citrus halimii Stone. J. Agr. Food Chem. 35:716-720.

Hedin, P. A., V.E. Langhans, and C.H. Graves, Jr. 1979. Identification of juglone in pecan as a possible factor of resistance to Fusicladium effusum. J. Agr. Food Chem, 27:92-94.

Merck \& Company. 1983. The Merck Index. 10th ed. Merck \& Co., Richway, N.J.

Prasad, R.B.N. and P.-G. Gulz. 1990. Surface waxes from leaves and fruits of walnut. Photochemistry 29:2097-2099.

Smith, M.R. and R.F. Severson. 1992. Host recognition by the blackmargined aphid (Homoptera: Aphididae) on pecan. J. Entomol. Sci. 27:93-112.

Thompson, T.E. and L.J. Grauke. 1990. Pecans and hickories (Carya). Acta Hort. 18:839-904.

Wood, B. W., T.R. Gottwald, and C.C. Reilly. 1988. Pecan phylloplane chemicals influence germination of pecan scab conidia. J. Amer. Soc. Hort. Sci. 113:616-619. 